\title{
A produção de modelos matemáticos a partir da Robótica Educacional no contexto do Ensino Médio
}

\author{
Deive Barbosa Alves ${ }^{1}$ \\ Professor Adjunto da Universidade Federal do Tocantins \\ Fernando da Costa Barbosa ${ }^{2}$ \\ Professor Adjunto da Universidade Federal de Goiás \\ Rafael Peixoto ${ }^{3}$ \\ Professor Adjunto da Universidade Federal do Triângulo Mineiro \\ Vanessa de Paula Cintra ${ }^{4}$ \\ Professora Adjunta da Universidade Federal do Triângulo Mineiro
}

Resumo. Este trabalho traz discussões de resultados de investigações de como trabalhar e explorar a Robótica Educacional (RE) com Matemática no Ensino Médio. Fazemos isso a partir de pesquisas ocorridas no âmbito do Ensino Médio de duas escolas públicas. O método adotado na escola 1 perpassa pelo estudo de modelos matemáticos implícitos na ideia de projetos de trabalho, partindo do seguinte princípio: identificar um problema, criar a solução, entender o modelo matemático presente na solução e desenvolver a solução em forma de um protótipo robótico. Na escola 2 a partir de um robô buscaram identificar os conhecimentos matemáticos que podem ser estudados e assim, desenvolveram ações investigativas com os alunos. Concluímos que as diferentes abordagens utilizando Robótica Educacional entrelaçaram a Modelagem Matemática e a Cultura Digital, e os processo de desenvolvimento possibilitaram os alunos serem autores de tecnologias.

Palavras-chave. Robótica, Escola Pública, Lego Arduino

\section{Introdução}

Há mais de uma década Papert (2000) atribui às tecnologias o caminho para se conseguir alcançar a construção de "grandes ideias". Em seu discurso Papert, menciona que é importante compreender que o principal, no ato educativo, está em produzir ideias a partir de objetos reais. Para ele a tecnologia digital, o computador, é o meio pelo qual se pode simular. Ter o poder de construir uma versão do mundo com a tecnologia, um micromundo de possibilidades de investigação, pesquisa, aprendizagem e ensino. São ideias

\footnotetext{
${ }^{1}$ deive@mail.uft.edu.br

${ }^{2}$ fcbarbosa@ufg.br

${ }^{3}$ rafael.peixoto@uftm.edu.br

${ }^{4}$ vanessa.cintra@uftm.edu.br
} 
fortes pensando em uma ótica de construção de espaços de ensino que trabalhe com modelos, microrrepresentações do mundo em conexão com a tecnologia, a ciência e a construção de protótipos. A apropriação das tecnologias em um movimento de desenvolvimento de um ambiente de aprendizagem Matemática tem crescido, levando em consideração principalmente a Cultura Digital das crianças e adolescentes.

É justamente na referência de Seymour Papert e seus companheiros de pesquisa e trabalho que surge a Robótica Educacional (RE). São diversas as interpretações e definições, tais como em Rocha (2006, p. 52), por exemplo, que entende como a superação do processo de montar peças, ela orienta num processo de mudança dos sujeitos envolvidos no ensino e aprendizagem, ou seja, o professor e o aluno ganham novos papéis, que sofrem "mudança de postura, diálogo, cooperação, metodologia, dúvida e indagação, além de significação". Compreendemos que a robótica até então é vista essencialmente como um recurso poderoso ao desenvolvimento cognitivo do aluno, capaz de ressignificar a forma de aprender os conhecimentos científicos.

A RE pode ser trabalhada com materiais proprietários, produtos industrializados para esse fim, como por exemplo kits: da Modelix, da LEGO entre outros. Quando o kit possui uma patente, é pronto e muitas vezes vem acompanhado de material didático, essa robótica denominamos de proprietária, agora existe também o trabalho com a Robótica Pedagógica Livre. Pensando nesses materiais, como eles podem ser utilizados no processo de ensino e aprendizagem de Matemática no Ensino Médio?

\section{Metodologia}

Este trabalho traz reflexões de investigações fundamentadas na pesquisa qualitativa, que segundo em Rey (2005, p. 105) é "um processo aberto submetido a infinitos e imprevisíveis desdobramentos". As pesquisas ocorreram em duas escolas públicas, sendo uma de Ensino Médio e cursos técnicos, que atribuiremos como escola 1, já a escola 2 oferecia apenas o Ensino Médio regular. Nessas escolas, foram propostos projetos de trabalho com Robótica Educacional a serem realizados no contraturno das atividades regulares dos alunos. Na escola 1, a abordagem e o material foram livres, tendo como base principal para construção do protótipo placa de programação Arduino. Já na escola 2, foi utilizado kit proprietário de robótica da LEGO Educacional.

Cada projeto pensou no ensinar Matemática, pensando na Cultura Digital dos alunos e no caso em especial da escola 1, desenvolver um projeto aplicado a formação do curso técnico dos alunos envolvidos, ou seja, curso de Meio Ambiente Integrado ao Ensino Médio. Essas pesquisas obtiverem diferentes resultados, no entanto convergem em uma proposta comum, o ensino da Matemática e é o que discutimos nesse texto.

A metodologia de trabalho adotada na escola 1, partiu do seguinte princípio: identificar um problema, criar a solução, entender o modelo matemático presente na solução, desenvolver a solução em forma de um protótipo robótico. Essa direção, perpassa pelo estudo de modelos matemáticos implícitos na ideia do projeto. A programação necessita dessa compreensão para se construir o algoritmo de programação. Já na escola 2, a metodologia seguiu um percurso diferente, a partir de um robô buscou-se identificar inicialmente os 
conhecimentos matemáticos que podem ser trabalhados e somente assim foram desenvolvidas ações investigativas com os alunos. Nesse processo, o robô se torna um instrumento de conexão com conhecimentos matemáticos já estudados pelos alunos ou que ainda será estudado.

\section{Desenvolvimento}

As pesquisas foram conduzidas e aprovadas por um comitê de ética e apresentamos dois resultados relevantes, que foi a construção e uso do robô irrigador pela escola 1 e o uso do robô castor bot pela escola 2. São duas produções, as quais foram instrumentos base para o desenvolvimento de um ambiente de aprendizagem tanto tecnológico quanto matemático.

\subsection{O robô irrigador}

O início dos trabalhos deu-se pelos alunos, com a formulação do seguinte problema: "será que a produção de uma tecnologia (um robô irrigador), que indica o consumo de água das plantas, favorece a economia de água na agricultura?". Após a formulação os alunos passaram para a investigação, iniciando procuraram definir o que seria um robô e encontraram a definição de Souza (2010) que argumenta que um robô é um dispositivo mecânico articulado reprogramável capaz de forma autônoma e recorrendo à sua capacidade de processamento: manipular objetos, tomar decisões sobre o que é necessário ser feito com base nas informação oferecidas e obter informações do meio utilizando sensores.

O processo investigativo levou o grupo a estudar para criar o sensor de umidade de solo. Usaram um estudo publicado pelos autores Griffiths e Griffiths (2013, p. 211) que indicam o uso de pregos galvanizados, contudo lixar a parte galvanizada estava interferindo na condução da eletricidade. O problema é que, ao lixar o prego, tem um processo de oxidação que também interfere na leitura da resistência elétrica. Usamos dois pregos soldados a quinze centímetros de fios. Um dos fios foi conectado em uma das "pernas" de um resistor de $10 \mathrm{Kohm}$ e colocada na porta A5 do Arduino, a outra "perna" do resistor foi conectado à porta GND, "terra", da plataforma. O segundo prego foi conectado à porta Vcc, de 5 volts, do Arduino.

Pautando-se em Aloi (2012) os alunos criaram também um circuito de proteção para que, com segurança, o Arduino que trabalha com corrente elétrica continua pudesse controlar a bomba d'água que funciona com corrente elétrica alternada. Os alunos escolheram trabalhar com relé, um dispositivo eletromecânico que controla a corrente alternada só ligando e desligando a carga. O esquema de montagem do robô irrigador, com base no Arduino Uno, é ilustrado na Figura 1.

Para o funcionamento do sensor de umidade estabelecemos que os pregos quando colocados no solo ficaria a uma distância de cinco centímetros um do outro e ambos a uma profundidade de dez centímetros. Além disso, esse tipo de sensor de umidade necessita que o mesmo seja calibrado, o que pode ser feito com um copo com água. Os valores durante a calibração foram os seguintes: Sensor fora do copo d'água, sem encostar em nada e valor "0" (zero) e Sensor dentro do copo com água: "711". 


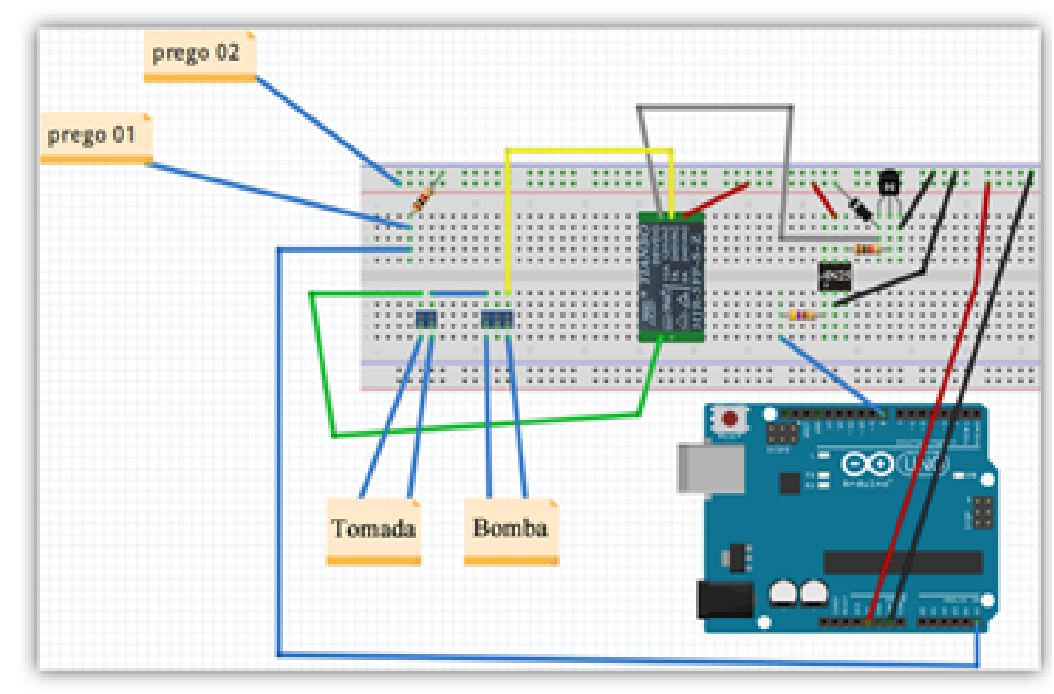

Figura 1: Circuito eletroeletrônico do robô irrigador (Fonte: Alves (2017)).

Para uma melhor compreensão, a porta analógica do Arduino lê o valor de um pino analógico especificado e a placa Arduino possui "um conversor analógico-digital 10 bts de 6 canais (8 canais nos Mini e Nano, 16 no Mega, 7 canais em placas MKR). Isso significa que este irá mapear tensões entre 0 e a tensão operacional $(5 \mathrm{~V}$ or $3.3 \mathrm{~V})$ para valores inteiros entre 0 e 1023" (ARDUINO, 2019, p. 1).

Contudo os alunos queriam que o Arduino retornasse esses valores em porcentagem, para facilitar para o usuário o entendimento de quão seco o solo estava. Os alunos decidiram, ainda, que o robô iria molhar as plantas quanto o solo estivesse com uma umidade abaixo de $60 \%^{5}$. Todo esse processo envolve entender as necessidades das plantas e o modelo matemático da placa Arduino, que precisa converter os valores analógicos de 0 a 711 para porcentagem do solo. Segundo Arduino (2016), o modelo matemático de conversão é dado pela função:

$$
\operatorname{map}\left(\text { valor }, M i_{a}, M a_{a}, N_{m i}, N_{m a}\right)=\left[\left(\text { valor }-M i_{a}\right) \cdot \frac{\left(M a_{a}-M i_{a}\right)}{\left(N_{m a}-N_{m i}\right)}\right]+N_{m i},
$$

onde valor é o número a ser convertido, $M i_{a}$ é o limite inferior do intervalo de valores atuais, $M a_{a}$ é o limite superior do intervalo de valores atuais, $N_{m i}$ é o limite inferior do novo intervalo de valores a ser mapeados, e $N_{m a}$ é o limite superior do novo intervalo de valores a ser mapeados.

Como os alunos obtinham valores de 0 a 711 unidades do Arduino usaram o modelo matemático map para efetuar o mapeamento de um valor desse intervalo numérico para outro valor no intervalo de 0 a 100 por centos. Assim eles mapearam os valores que foram de 0 a 711 para um novo valor no intervalo entre 0 a 100 por cento. Dessa forma,

\footnotetext{
${ }^{5}$ Para a escolha do valor de $60 \%$ não houve nenhuma investigação, pois o tempo não nos permitiu estudar a porcentagem de umidade em diferentes tipos de solos, bem como de diferentes tipos de plantas.
} 
$p=\operatorname{map}($ valor $, 0,711,0,100)$. Os valores atuais da porta analógica foram lidos a partir de uma variável chamada valor, e os novos valores mapeados em porcentagem foram gravados em uma variável de nome $p$.

\subsection{Robô Castor Bot}

Na segunda escola, utilizamos a montagem de um modelo de robô denominado "Castor Bot", retirado de um site de montagens livres chamado "nxtprograms.com". Através desta montagem é possível desenvolver diferentes atividades. O material utilizado para confeccionar esse robô é da LEGO Educacional, sendo passível de fazer modificações com encaixe e desencaixe de peças, pois seguem os mesmos princípios dos brinquedos da LEGO.

O desenvolvimento do protótipo também envolve o controle de programação e esta deve ser lógica e eficiente, não permitindo falhas. Assim, o simples processo de fazer andar medidas fixas, exige conhecimentos matemáticos simples para resolver o problema e obter os valores necessários para inserir no código de programação, sendo que a programação admite valores números de entrada como ângulo, tempo ou rotações. A partir das nossas discussões foi possível formular um problema: Dado um robô sobre uma superfície plana, temos que a roda é perpendicular a qualquer parte desse plano e concêntrica ao motor que propulsiona o movimento do robô. Dessa forma, quantas rotações dessa roda e, portanto, do motor, são necessárias para que o robô gire em um determinado ângulo?

Uma situação comum é posicionar o robô no centro de uma sala e, quando o mesmo identificar um obstáculo, ele pode fazer um giro de $90^{\circ}$ para que possa desviar. Essa ação tem duas possibilidades de execução: travar uma das rodas enquanto a outra exerce o movimento; ou fazer com que as duas se movimentem simultaneamente. Como podemos perceber na figura seguinte.

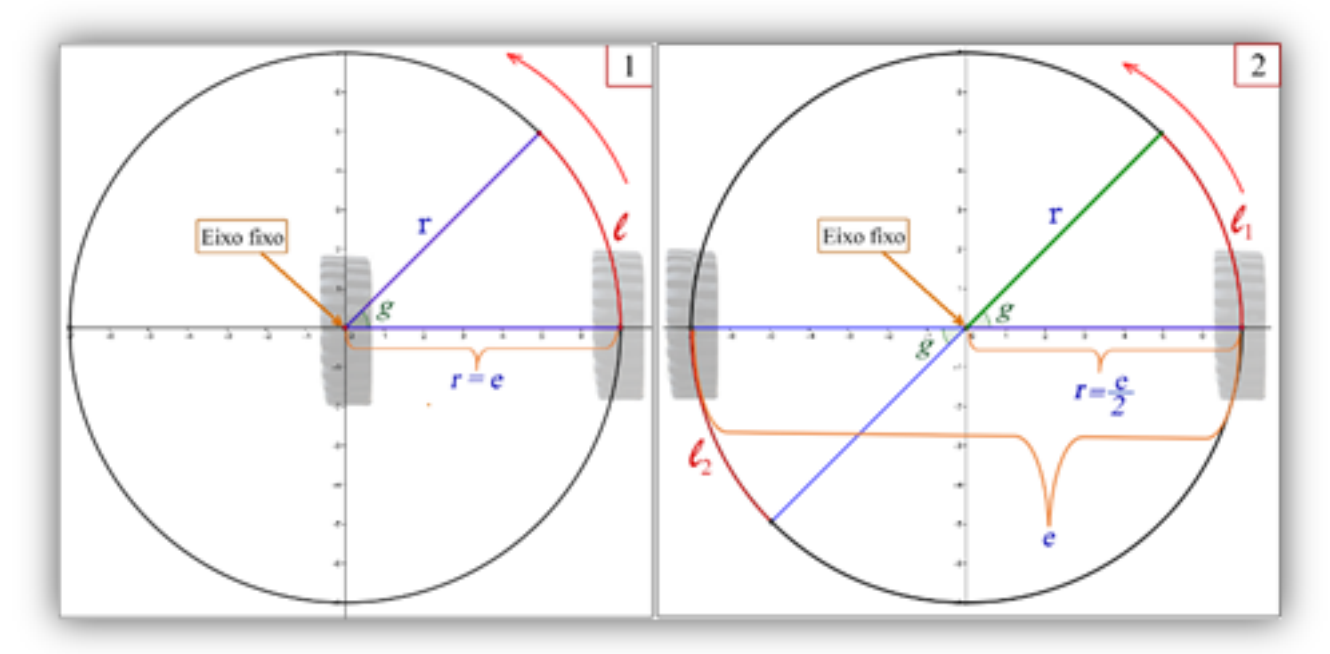

Figura 2: Giros do robô (Fonte: Barbosa (2016, p.361)).

A solução desse problema pode ser calculando toda vez que for necessário ou entender 
e construir o a formula a partir dos modelos matemáticos que facilite a obtenção dos resultados necessários a programação. Assim, pensando em obter o número de rotações de forma a satisfazer a opções acima de movimento, necessita entender o funcionamento do robô, bem como sua largura, as possíveis rodas que ele pode ter. Assim, se o robô precisa girar o corpo um determinado grau, com uma das rodas travadas, é preciso determinar o número de rotações que o motor exercera sobre a roda, pois as programações não aceita o valor em graus. Essa informação é obtida através do modelo (BARBOSA,2016,p.361):

$$
\rho=\frac{\frac{g \cdot \pi \cdot e}{180^{\circ}}}{d \cdot \pi}=\frac{g \cdot e}{d \cdot 180^{\circ}},
$$

onde $\rho$ são as rotações, $g$ os graus que o corpo do robô irá girar, $d$ o diâmetro da roda e $e$ a distância entre as rodas. Adotando os mesmos princípios, quando robô realiza o movimento com as duas rodas, o modelo obtido é $\rho=\frac{g \cdot e}{d \cdot 360^{\circ}}$. Assim, duas situações, permitem rever modelos matemáticos aprendidos e muitas vezes ficam em desuso, sendo aplicados e explorados. Através desses resultados, obter graus e tempo são conversões de unidades.

\section{Considerações finais}

As discussões apresentadas trazem diferentes abordagens de como a Robótica Educacional pode ser utilizada no processo de ensino e aprendizagem da Matemática no Ensino Médio. Nessa aprendizagem, em que existem pessoas querendo fazer coisas, o conhecimento cientifico-tecnológico é uma ação transformadora do humano, algo a ser construído na coletividade, o qual se fez nas investigações, com informações que buscamos na produção de um robô irrigador por um grupo de alunos, que estavam em um constante movimento de transformar curiosidades espontâneas em curiosidades epistemológicas. De acordo com Freire (2011, p. 81), o conhecimento só existe "na invenção, na reinvenção, na busca inquieta, impaciente, permanente, que os homens fazem no mundo, com o mundo e com os outros. Busca esperançosa também".

A capacidade de autonomia, criatividade e produção devem ser mais exploradas com os estudantes, buscando uma diferenciação do currículo educacional muitas vezes praticado atualmente, que é "passivo, baseado em aulas expositivas não é somente uma prática pedagógica pobre. É o modelo de ensino mais compatível com a promoção da autoridade dominante na sociedade e com a desativação da potencialidade criativa dos alunos" (FREIRE; SHOR 2011, p. 28).

As experiências deste trabalho educativo com Matemática lendo o mundo do Arduino, para criar um robô irrigador para economia de água, foi cansativo, envolvente, divertido e recompensador. Assim, implementou-se um robô entrelaçamento da Modelagem Matemática e da Cultura Digital tornando os alunos autores de tecnologia. Experiência que afetou a forma dos estudantes de verem as coisas do mundo, ela, a experiência, abre possibilidades para se criar desde máquinas automatizadas aos robôs, de acordo com nossa motivação e vontade. Assim aprendeu-se que com e a partir da Matemática é possível transformar e criar novas realidades. 
Além dos materiais serem livres, os estudantes tinham a liberdade de escolher e fazer diferente. Tanto que o grupo foi criativo ao expor seu trabalho. Considerando que o seu primeiro robô foi a reprodução de um já existente, mostrar um robô funcionando no local de apresentação atraiu a atenção de colegas e pais, um verdadeiro reconhecimento ao esforço e trabalho daquele grupo. Ressaltamos a importância dos alunos perceberam que são capazes de fazer e que os saberes matemáticos promovidos pela Robótica Experimental é uma Matemática focada na transformação em que se aprende pela ação de uma pesquisa cientifica-tecnológica.

\section{Referências}

[1] R. Aloi. Optoacopladores. 2012. Disponível em: http://migre.me/wmdbF. Acesso em: 17 jul. 2015.

[2] D. B. Alves. Modelagem Matemática no Contexto da Cultura Digital: uma Perspectiva de Educar pela Pesquisa no Curso de Técnico em Meio Ambiente Integrado ao Ensino Médio. Tese de Doutorado, UFU, 2017.

[3] Arduino. Serial. 2016. Disponível em: https://goo.gl/9rHwbT. Acesso em: 12 mar. 2016.

[4] Arduino. Entradas e Saídas Analógicas. 2019. Disponível em: https://goo.gl/5jhNUj. Acesso em: 10 mar. 2019.

[5] F. C. Barbosa. Rede de Aprendizagem Em Robótica: Uma Perspectiva Educativa De Trabalho Com Jovens. Tese de Doutorado, UFU, 2016.

[6] P. Freire. Pedagogia da Autonomia: Saberes necessários à prática educativa. Paz e Terra, São Paulo, 2011.

[7] P. Freire e I. Shor. Medo e ousadia: o cotidiano do professor. Tradução Adriana Lopes. 2 edição, Paz e Terra, Rio de Janeiro, 2011.

[8] D. Griffiths e D. Griffiths. Use A Cabeça! C. Alta Books, São Paulo, 2013.

[9] S. Papert. What's the big idea? Toward a pedagogy of idea power. Ibm Systems Journal. New York, 720-729, 2000.

[10] F. L. G. Rey. Pesquisa Qualitativa e Subjetividade: os processos de construção da informação. Tradução Marcel Aristides Ferrada Silva. Pioneira Thomson Learning, São Paulo, 2005.

[11] R. ROCHA. Utilização da robótica pedagógica no processo de ensino aprendizagem de programação de computadores. Dissertação de Mestrado, CEFET-MG, Belo Horizonte, 2006

[12] F. Souza. Automação Industrial e Robótica. 2010. Disponível em: https://goo.gl/tJCQyQ. Acesso em: 10 nov. 2015. 